\title{
CONTRIBUIÇÕES DO LÚDICO PARA O DESENVOLVIMENTO INFANTIL NA CLÍNICA DE NEUROPSICOLOGIA
}

\section{ARTIGO ORIGINAL}

SILVA, Vanussa Sampaio Dias da ${ }^{1}$

CARVALHO, Priscila Viviane de Sousa ${ }^{2}$

SILVA, Vanussa Sampaio Dias da. CARVALHO, Priscila Viviane de Sousa. Contribuições do lúdico para o desenvolvimento infantil na clínica de neuropsicologia. Revista Científica Multidisciplinar Núcleo do Conhecimento. Ano 05, Ed. 11, Vol. 03, pp. 49-63. Novembro de 2020. ISSN: 2448-0959, Link de acesso: https://www.nucleodoconhecimento.com.br/psicologia/clinica-deneuropsicologia

\section{RESUMO}

O estudo propor-se a avaliar as contribuições do lúdico no desenvolvimento infantil e sua viabilidade na clínica em neuropsicologia, destacando também o seu potencial de comunicação, expressão e projeção o qual favorece ao neuropsicológo um melhor diagnóstico e intervenção. Propomos pesquisar as concepções dos teóricos sobre a importância da ludicidade para o desenvolvimento de áreas e habilidades indispensáveis à criança e a forma como esta atividade se constitui em um dos principais recursos na clínica de neuropsicologia infantil. As hipóteses são de que a atividade lúdica contribui significativamente para o desenvolvimento infantil, é estimulante e motivadora, além de se constituir em um recurso importante na clínica

${ }^{1}$ Graduação em Bacharel em Psicologia pela Universidade Federal do Maranhão, pós-graduação em Psicopedagogia pelo CAPEM, Neuropsicologia pelo SINAPSE e pela UEMA pós graduação em Educação Especial e Inclusiva.

2 Orientadora. Mestrado em Letras. Graduação em Licenciatura Plena em Letras/Inglês. 
com crianças. A metodologia utilizada será do tipo bibliográfica, qualitativa descritiva. Este estudo está organizado em: A neurociência e o lúdico na construção do desenvolvimento infantil, a psicologia e o lúdico no desenvolvimento infantil e o lúdico como recurso terapêutico de diagnóstico e intervenção na clínica infantil, sendo que abordamos nestes as principais concepções teóricas sobre as contribuições do lúdico na infância, até entrar na discussão deste como recurso lúdico contribui para a clínica no diagnóstico e intervenção, levando em conta a importância que tem este para tratamento de crianças com dificuldades e/ou atraso no desenvolvimento.

Palavras-chave: Lúdico, recurso terapêutico, neuropsicologia.

\section{INTRODUÇÃO}

A neurociência e a psicologia em áreas distintas, mas interligado por vezes, tem dado inúmeras contribuições para compreendermos como se efetua o desenvolvimento infantil, paralelamente estudiosos destas áreas tem se empenhado em pesquisar sobre importantes recursos e atividades, sobretudo o lúdico, que contribuam para estimular e motivar o desenvolvimento na infância. Estudos e experiências foram descritos e relatados em literaturas sobre a eficiência do lúdico também na clínica infantil em neuropsicologia.

A temática foi escolhida por reconhecer que o brincar tem apresentado no desenvolvimento de crianças e no uso deste como recurso na clínica infantil de neuropsicologia para diagnóstico e intervenção.

As hipóteses são de que a atividade lúdica contribui significativamente para o desenvolvimento infantil, é estimulante e motivadora, além de se constituir em um recurso diagnóstico e terapêutico importante na clínica com crianças que apresentam dificuldades e/ou atraso no desenvolvimento, pois sabe-se que o ato de brincar é algo intrínseco, espontâneo e projetivo e por esse motivo surge como peça fundamental para comunicação, observação, coleta de informações e intervenção no processo de atendimento clínico. 
O estudo também busca contribuir para o campo do desenvolvimento infantil em diversos aspectos e campos de intervenção, sobretudo como recurso de apoio ao terapeuta na área de neuropsicologia clínica.

A pesquisa tem como área de conhecimento as ciências biológicas e humanas, visa descobrir quais as contribuições do lúdico no desenvolvimento infantil e na Clínica de neuropsicologia, salientando-se quais e de que maneira essas ações lúdicas (jogos, brincadeiras, desenhos, contação de histórias, entre outros) tem uma importante contribuição na identificação das dificuldades neurológicas, emocionais e educacionais da criança.

Pesquisas como está nas áreas de neurociência e psicologia sobre o brincar, também contribuem para a motivação da adoção e ao incentivo dessa atividade em inúmeras situações da primeira fase da vida.

Buscar conhecer melhor este tema também nos traz a possibilidade de apontar quais tipos de áreas e habilidades cognitivas o lúdico auxilia no desenvolvimento e reabilitação, destacando o que os autores da neurociência e da psicologia pensam a respeito e suas contribuições na clínica e na reabilitação para avanços no desenvolvimento e na aprendizagem. Estaremos salientando as falas de autores sobre o lúdico e sua viabilidade, entre eles Piaget (1975), Vygotsky (2000), Relvas (2009 e 2015), Meyer (2004), Cunha (1994), Maluf (2004), Kishimoto (2002), que defendem o brincar como importante atividade para o desenvolvimento e o reconhecem como recurso para o trabalho de diferentes profissionais.

Este estudo está organizado em capítulos: A neurociência e o lúdico na construção desenvolvimento infantil, a psicologia e o lúdico no desenvolvimento infantil e o lúdico como recurso terapêutico de diagnóstico e intervenção na clínica infantil, sendo que abordamos nestes as principais concepções teóricas sobre as contribuições do lúdico na infância, até entrar na discussão deste como recurso lúdico contribui para a clínica no diagnóstico e intervenção, levando em conta a importância que tem este para o tratamento de crianças que apresentam dificuldades e/ou atraso quanto ao desenvolvimento. 
Por fim, o trabalho busca provar a efetividade do uso do lúdico enquanto recurso diagnóstico e terapêutico na clínica, destacando de que forma se dá essa contribuição.

\section{A NEUROCIÊNCIA E O LÚDICO NA CONSTRUÇÃO DO DESENVOLVIMENTO INFANTIL}

A neurociência como ciência quando questionada sobre as contribuições do lúdico no desenvolvimento infantil, vai buscar respostas sobre esse importante e intrínseca atividade para a infância saudável. O lúdico faz parte de uma temática muito estudada por diversas áreas e apresenta um grande viés de possibilidades de atuação, seja como atividade de ócio, seja como importante recurso e aliado nas diversas áreas como educação, psicologia e a própria neurociência interessadas nos processos cognitivos da aprendizagem da criança.

Vemos hoje nos diversos estudos na área de Neurociência que está vem sugerindo novos caminhos para a clínica de neuropsicologia com crianças e adolescentes, pontuações que aguçaram o desenvolvimento deste estudo. É na prática clínica que nós neuropsicólogos nos confrontamos constantemente com problemas de desenvolvimento, levando-nos à necessidade de compreender as capacidades e potencialidade cognitivo presente nos indivíduos atendidos, atuando e intervindo junto a estes problemas, buscando na própria neurociência as respostas e alternativas para melhoria em nossa intervenção.

A Neurociência é uma área de conhecimento que estuda mais profundamente a compreensão do cérebro humano, bem como seu desenvolvimento e funcionamento, envolvendo diferentes profissionais e revolucionando os estudos científicos. Ela dá respostas confiáveis nas questões sobre a aprendizagem humana, auxiliando na compreensão daquilo que é comum a todos os cérebros. (RELVAS, 2018, p.1).

Relvas (2015) chama a atenção para as diversas limitações funcionais possíveis existentes no sistema nervoso central e a necessidade da neurociência se preocupar não somente em estudar essas funções e suas limitações, mas em aprender a aplicar metodologias e recursos didáticos com a finalidade de potencializar as redes neurais dos educandos corretamente. Ainda destaca que é fato poder resolver ou amenizar 
diversas dificuldades de aprendizagem, desde que o educando seja estimulado a estímulos neurais, uma vez que se tenha o conhecimento dos processos e princípios pelos quais passam o cérebro, conhecendo e identificando as suas áreas funcionais, com objetivos de estabelecer rotas alternativas para aquisição da aprendizagem, utilizando-se de recursos sensoriais, com instrumentos do pensar e do fazer.

Segundo Relvas (2015) para desencadear a aprendizagem cognitiva necessitamos de um processo complexo e dinâmico que acarretaram modificações de estruturas funcionais do SNC (Sistema Nervoso Central). As transformações surgem a partir de um ato motor e perceptivo elaborado no córtex cerebral. Acreditamos que o lúdico tem um grande potencial estimulador dos sentidos e seja capaz de acessar áreas e funções nervosas superiores e desencadear ações cognitivas de diversos comandos necessárias à aprendizagem.

Sem as contribuições da neuropsicologia, seria impossível que nós estudiosos e terapeutas discutíssemos propostas e caminhos para potencialização das redes neurais e o uso adequado de recursos e métodos de intervenção na reabilitação de funções superiores prejudicadas no desenvolvimento de crianças atendidas na clínica. Como destacado por Relvas (2015) são a partir da estimulação desses recursos sensoriais, desencadeados no uso do lúdico, por exemplo, que podemos obter respostas à estimulação dos instrumentos do pensar e do fazer

O pesquisador Sousa (2005 apud GUIMARÃES; SILVA 2017, p.126), ressaltam que:

O cérebro gosta de brincar porque essa atividade estimula o sistema límbico (responsável pelo processamento das emoções) e produz bem estar, prazer e alegria. As brincadeiras, por serem significativas para a rede neural, fortalecem as sinapses (circuitos neurais) que interligam o sistema límbico ao neocórtex, proporcionando a tomada de decisões, ou seja, habilidades racionais que favorecem a aprendizagem.

Portanto, percebe-se que essas emoções auxiliam na aprendizagem cerebral.

As constantes pesquisas e relatos de importantes neurocientistas reforçam a tese de que as informações obtidas pelas crianças se fixam na memória por um tempo maior, 
devido o seu estímulo, e desta forma irão gerar de significativos mecanismos de ativação das aprendizagens.

O intuito de nós pesquisadores é levar as orientações e indicações de importantes pesquisadores apontados neste estudo, para descobrir, em tese, como o lúdico está desencadeando organicamente e emocionalmente sensações e sentimentos que o torna potencializador de importantes gatilhos da aprendizagem a partir do entendimento de como o cérebro funciona no momento da atividade lúdica.

Segundo a neurociência, as brincadeiras liberam transmissores que aperfeiçoam o aprendizado sem provocar depressões, esgotamentos ou estresses e preparam o educando em novas habilidades ao longo de sua aprendizagem mais formal. Com o brinca o cérebro libera dopamina, conhecido como o hormônio do prazer e a noradrenalina. Dessa forma, diversos outros órgãos são ativados e aprimoram a plasticidade cerebral. Teremos como um efeito global uma ampla colaboração para o aprendizado. (GUIMARÃES; SILVA, 2017, p.127).

Os diversos autores apontam para o lúdico como atividade promotora de desenvolvimento e bem estar na criança, essa importante atividade, organicamente natural e intrínseca, é algo instintivo e natural que o bebê já traz como potencialidade, ninguém nasce sabendo brincar, mas ninguém nasce sem nenhuma habilidade pra desenvolver o lúdico. É uma atividade iniciada na infância, completa ao desenvolvimento e indispensável ao amadurecimento saudável.

Maluf (2004) enfatiza que no desenvolvimento da criança, ela irá aprender inúmeras brincadeiras e com isso ela irá interagir com outras crianças, as brincadeiras irão evoluir, mas o interesse que era observado nos estágios iniciais não serão perdidos e isso só é possível quando a mesma respeita seu próprio ritmo. O brincar desperta suas tendências à experimentação.

Kishimoto (2002) defende que toda Atividade Lúdica tem sua função, e quem as práticas terão a chance de um bom desenvolvimento psicológico e motor.

Por meio de atividades lúdicas, o sujeito-aprendiz exercita habilidades das funções cognitivas, que são: percepção, atenção, memória, linguagem e funções executivas. 
O lúdico proporciona condições adequadas ao desenvolvimento físico, motor, emocional, cognitivo e social, em que ações voltadas à ludicidade estimulam a vontade de aprender, torna-se a porta de entrada do mundo exterior, facilitando a interpretação do cérebro no processo cognitivo. (MALUF, 2004).

Pode-se destacar nessa pesquisa a grandeza do desenvolvimento cognitivo que é a fala na criança, que segundo um trabalho divulgado no site da FAPESP, por Schimitd (2019) em sua tese aponta que a linguagem é uma importante dimensão a ser estimulada e desenvolvida ainda na primeira infância cujo desenvolvimento do repertorio verbal depende de um aparato biológico apropriado e da manipulação de contingencias ontogenéticas e culturais pela comunidade verbal. Fato a ser destacado, pois sendo a criança um ser ainda imaturo em sua capacidade orgânica, não apresentará um repertório vocal desenvolvido que lhe forneça recursos para uma boa compreensão e argumentação verbal com o terapeuta.

A despeito disso, observa-se que o brincar favorece e auxilia não entendimento de situações e sentimentos o que ainda não disponibiliza de recursos e maturidade para falar, mas que na situação lúdica a criança manifesta. Segundo Silveira e Silvares (2003 apud GADELHA; MENEZES 2004) atividades como brincadeiras, dramatizações e outras, podem evidenciar o comportamento verbal referente ao destaque de sentimentos e de estados de carência de afeto, além de poder estreitar relacionamentos.

Froebel (1912, apud KISHIMOTO 2002, p.27) "concebe o brincar como atividade livre e espontânea, responsável pelo desenvolvimento físico, moral e cognitivo; e os dons dos brinquedos como objetos que subsidiam as atividades infantis". O brincar, enquanto atividade infantil, não tem somente a capacidade de desenvolver potencialidades, mas ela por si só é motivadora e convidativa, a criança dificilmente recusa os apelos de um brinquedo ou uma brincadeira. A desmotivação frente a uma atividade pode ser indicativa de problemas. Seja de origem orgânica ou psíquica.

Para Cunha (1994, p. 11), "é brincando a criança desenvolve suas potencialidades e não se sente cansada". Os desafios ocultos no brincar fazem com que a criança pense 
e alcance níveis melhores de desempenho. Criança é por si só, curiosa e possui a imaginação aguçada, está conectado ao mundo e necessita desse exercício exploratório diariamente para desenvolver-se de forma saudável.

Maluf (2004) entre outros aspectos favoráveis do brincar destaca que a brincadeira se torna um momento em que a criança demonstra sua criatividade, imaginação, inteligência e potencialidades. Por meio do lúdico, podem desenvolver capacidades indispensáveis à futura atuação profissional, como boa atenção, boa concentração e outras habilidades psicomotoras.

Dentro desta perspectiva, acreditamos que o lúdico como recurso de desenvolvimento à aprendizagem se constitui em um importante aliado às redes neurais e todo processo de desenvolvimento, se constituindo interesse para a neurociência.

\section{A PSICOLOGIA E O LÚDICO NO DESENVOLVIMENTO INFANTIL}

Ressalta-se que as brincadeiras e jogos são de primordial importância no que se refere ao desenvolvimento infantil e no ponto de vista da Psicologia, pois ao brincar a criança resgata de forma lúdica o prazer em aprender, deixando de ser algo imposto e passa a ser encarado de forma natural.

Logo, para Kishimoto (2002, p.1):

O poder de tomar decisões, expressar sentimentos e valores, conhecer a si, aos outros e o mundo, de repetir ações prazerosas, de partilhar, expressar sua individualidade identidade por meio de diferentes linguagens, de usar o corpo, os sentidos, os movimentos, de solucionar problemas e criar. Ao brincar a criança experimenta o poder de explorar o mundo dos objetos, das pessoas, da natureza e da cultura, para compreendê-lo e expressá-lo por meio de variadas linguagens. Mas é no plano da imaginação que o brincar se destaca pela mobilização dos significados. Enfim, sua importância se relaciona com a cultura da infância, que coloca a brincadeira como ferramenta para a criança se expressar, aprender e se desenvolver.

Pode-se considerar que Guimarães e Silva (2017), levou em conta a importância da brincadeira colocando-a em "lugar de parte integrante do desenvolvimento da criança 
e que sem ela os pequenos perdem oportunidades preciosas de aprendizagens fundamentais para a construção de seu conhecimento" e seu bem-estar psicológico.

A ludicidade nos primeiros anos de vida é primordial para o crescimento, pois é por meio dela e seu estimulo será desenvolvido ações cognitivas, sensoriais e motoras, por exemplo, a fala, a linguagem que facilitará a interação e a socialização com outras crianças, sendo em brincadeiras fora do âmbito escolar ou até na pré-escola, onde possuem crianças com idades semelhantes ou idades diferentes, devendo do espaço em que a mesma estiver inserida. Desta forma Guimarães e Silva (2017, p.125), consideram que:

$\mathrm{Na}$ brincadeira com outros ou sozinha, a criança faz uso de todos os seus recursos para explorar o mundo e se conhecer, construir seu pensamento e trabalhar seus afetos, sua capacidade de ter iniciativa e ser sensível a cada situação, aprender a viver e se desenvolver. A atividade de brincar contribui para que as crianças compartilhem conhecimento, pertençam a um grupo, construam sua identidade, comuniquem-se consigo mesmas e com os outros, estabeleçam formas de relação com o outro, se apropriem e produzam cultura, exercitem a tomada de decisão e criem.

Não poderíamos deixar de direcionar dentro de um olhar da psicologia e sua relação com o lúdico na infância às teorias psicogenéticas de Jean Piaget e Levy Vygotsky.

Para compreendermos o pensamento de Piaget (1975, p.207) sobre o lúdico, ao qual destacou os jogos, o autor discorreu sobre conceitos como a acomodação e a assimilação, presentes em todas as etapas do desenvolvimento em processo contínuo, e enfatiza "[...] o jogo constituí o polo extremo da assimilação do real ao eu". Desta forma, Piaget (1975) ressalta que o jogo pode ser apresentado à criança nos anos iniciais, e destaca que nos primeiros estágios do desenvolvimento, o comportamento, em sua maioria convertia-se em jogo, dentro do processo assimilativo. E classificou os jogos em "Jogo de Exercício, Jogo Simbólico e o Jogo de Regra", presentes nas diferentes fazes e períodos da criança.

A brincadeira analisada sob a perspectiva sócio histórica é entendida como uma atividade social da criança, cuja natureza e origem específicas são elementos 
fundamentais para a construção da personalidade e compreensão da realidade. E, nas brincadeiras infantis a imaginação é usada, assim como a imitação e regras a serem respeitadas, que estão sujeitas a questões psicológicas, como: pensamento, linguagem, memória, atenção, percepção e aprendizagem, valorizando as características da infância com suas necessidades respeitando a idade cronológica, a função do brinquedo em especial para a criança inserida em um contexto sociocultural como fatores influenciadores da personalidade e formação da criança. (VYGOTSKY, 2000).

\section{O LÚDICO COMO RECURSO TERAPEUTICO DE DIAGNÓSTICO E INTERVENÇÃO NA CLÍNICA INFANTIL}

Em uma proposta de atendimento clínico, o neuropsicólogo deverá levar em conta a idade cronológica e os interesses da criança, sendo disponibilizados objetos e brinquedos em qualidade e quantidade satisfatórias as suas demandas. Estes brinquedos deverão ser variados em seus diferentes tipos de estímulos e áreas a serem trabalhadas, ora em atividades livres, ora sob mediação. As crianças avaliadas na clínica passam por diferentes etapas, com diferentes atividades e recursos, com o objetivo de identificar alterações no seu desenvolvimento e intervir de forma precoce, direcionando um plano de intervenção e orientações.

Algumas áreas de intervenção e clínica infantil são unânimes em reconhecer a importância do lúdico como recurso de diagnóstico e de manejo clínico terapêutico sendo foco de inúmeras pesquisas nas áreas de psicopedagogia, psicologia, neuropsicológica, pediatria, psiquiatria, entre outras.

Dentro da clínica infantil psicanalista, uma das principais representantes, Winnicott (1975) reconhece fundamentalmente a importância do lúdico na infância e em qualquer forma de intervenção com esta:

O natural é o brincar e o fenômeno altamente aperfeiçoado do século XX é a psicanálise. Para o analista, não deixa de ser valioso que se the recorde constantemente não apenas aquilo que é devido a Freud, mas 
também o que devemos à coisa natural e universal que se chama brincar. (WINNICOTT, 1975, p.63).

Weiss (2010), importante teórico da psicopedagogia clínica vai trazer a importância da relação terapeuta-método-paciente destacada por Winnicott (1975) para falar do encontro que se estabelece entre o terapeuta e o paciente quando se abre um espaço para brincar durante o diagnóstico, onde já se possibilita um movimento em direção a saúde e cura, pois de acordo com Winnicott (1975, p.59) "a psicoterapia se efetua na sobreposição de duas áreas do brincar, a do paciente e a do terapeuta. A psicoterapia trata de duas pessoas que brincam juntas". Por semelhante encontro, o neuropsicólogo, em um ato de brincar proporciona ao paciente esse encontro, que é terapêutico, criando espaços de intervenção e cura sobre os problemas de aprendizagem, tendo o bom conhecimento do manuseio desse recurso.

Por semelhante encontro, o neuropsicólogo, em um ato de brincar proporciona ao paciente esse encontro, que é terapêutico, criando espaços de intervenção e cura sobre os problemas de aprendizagem, tendo o bom conhecimento do manuseio desse recurso enquanto utilizá-lo. De acordo com Weiss (2010, p.73):

A sessão lúdica diagnóstica distingue-se da terapêutica, porque nessa o processo de brincar ocorre espontaneamente, enquanto na diagnóstica há limites mais definidos. Nesta última podem ser feitas intervenções provocadoras e limitadoras para se observar a reação da criança: se aceita ou não as propostas, se revela como quer ou pode brincar naquela situação, como resiste às frustrações, como elabora desafios e mudanças na situação etc.

Meyer (2004) vem reforçar a função primordial do brincar na infância e o quanto o brinquedo se torna um importante meio terapêutico e de intervenção por suas particularidades e ligação com o exercício da simulação do real, indispensáveis ao manuseio clínico na infância:

O brinquedo estimula a representação, a expressão de imagens que evocam aspectos da realidade. O brinquedo enquanto objeto, é o material que permite fluir o imaginário infantil. (...) o brinquedo acaba sendo o substituto dos objetos reais, podendo assim, manipulá-los. (...) $\mathrm{Na}$ brincadeira o sentido da realidade pode mudar: as coisas tornam-se 
outras. Os objetos podem assumir papeis diferentes daquilo que representam. (MEYER 2004, p.38).

Winnicott (1965 apud MALUF 2004), "coloca o brincar como uma área intermediária de experimentação para a qual contribuem a realidade interna e externa". Desta forma, a criança torna-se capaz de relacionar suas situações internas com sua realidade externa, tornando-se capaz de reagir ao contexto e de perceber-se no mundo.

Pereira (2004, p.40) destaca importantes e complexas ações cognitivas implicadas no brincar, ao declarar que "para brincar é preciso se comunicar e interpretar, a partir de uma decisão por parte daqueles que brincam".

Brincar, é observado no pensamento do autor como um processo de construção, é uma sucessão de decisões e regras a serem obedecidas dentro de um universo lúdico, partilhado ou não com outros, num atendimento clínico ou em outro ambiente. Há crianças que ora demandam brincarem sós, envoltas na sua ação, em outros buscam dividir o momento lúdico.

Segundo Wajkop (1999, p.38), quando o adulto se propõe a intervenção com a criança, intermediado por um recurso lúdico, é aconselhado, "ora como observador e organizador, ora como personagem que explicita ou questiona e enriquece o desenrolar da trama, ora como elo de ligação entre as crianças e o objeto".

As atividades lúdicas exigem um esclarecimento inicial, onde deverá sempre ser colocado a criança à vontade, salientando a brincadeira, o modo de brincar e a relação que tem com o terapeuta, onde o é apresentado como lúdico como atividade clínica diagnosticada. Desta forma, Weiss (2010, p.76) afirma que:

Por ser um jogo inerente ao homem, e por revelar sua personalidade integral de forma espontânea, favorece a obtenção de dados específicos e diferenciados em relação ao Modelo de Aprendizagem do paciente. Assim, aspectos do conhecimento que já possui, do funcionamento cognitivo e das relações vinculares e significações existentes no aprender, o caminho usado para o aprender e o não aprender, o que pode revelar, o que precisa esconder e como o faz podem ser claramente observados através do jogo. 
Observado na fala dos autores, o brinca se constitui em um recurso também terapêutico, um espaço para projeções e sublimações de sentimentos e experiências negativas, tão indispensáveis à cura em certos casos. Ao brincar, o terapeuta deve sempre que necessário direcionar a atividade, realizar intervenções e deixando claro o objetivo da brincadeira, dependendo do momento da criança para que esta, por meio do lúdico possa trabalhar sua impulsividade, agressividade, impulsividade, assim como aprender a lidar com a própria destrutividade. (OLIVEIRA, 2014).

Portanto, foi possível perceber que, assim como Oliveira (2014) que os autores citados acima, concordam e vê como é importante à utilização de brinquedos, brincadeiras e jogos como atividades terapêuticas clínica infantil e incentivam os profissionais, entre eles neuropsicólogos, a fazer uso desses materiais com conhecimento adequado, não só colocando apenas por colocar os brinquedos para as crianças, mas sabendo abstrair do momento lúdico, o melhor da criança, as hipóteses para origem de sua problemática e nele próprio um recurso de auxilio terapêutico.

Maluf (2004) nos chama a atenção para a participação do adulto na brincadeira com a criança, com a possível elevação do interesse da criança em brincar, de se sentir desafiada e prestigiada pelo adulto. $\mathrm{O}$ adulto, por sua vez, pode auxiliar a criança a novas experiências e descobertas enriquecendo o aprendizado.

Levando para a relação terapeuta- criança, onde o terapeuta está munido de técnicas, como adulto e profissional ele tem maiores condições de contribuir para o crescimento e progresso do paciente. Devemos como aponta Maluf (2004) ter um espírito aberto ao lúdico, reconhecer a sua importância para o desenvolvimento infantil. A relação entre brincadeira e o desenvolvimento da criança permite que se conheça com mais clareza importantes funções mentais, como o desenvolvimento do raciocínio, da linguagem. Importantes aspectos avaliados na clínica de neuropsicologia.

Gadelha e Menezes (2004, p. 62) revelam que:

Algumas estratégias lúdicas têm sido usadas por nós na prática clínica com os objetivos de favorecer a formação do vínculo com a criança, identificar os conceitos e as regras que governam seu comportamento, 
verificar sua relação com pessoas dos ambientes em que está inserida, identificar seus sentimentos em relação a si mesma, a determinadas pessoas e situações, treinar a solução de problemas cotidianos, desenvolver habilidades, trabalhar a autoconfiança e favorecer a concentração e o relaxamento.

Em estudo, foram pontuados de forma interessante pelas pesquisadoras em seu trabalho as principais estratégias lúdicas a serem desenvolvidas na relação terapêutica com a criança na terapia comportamental pelo psicólogo, compreendendo através do lúdico a interação da criança com o terapeuta, onde pode desenvolver habilidades diversas, pode trabalhar a autoconfiança e a autoestima da criança, desenvolve a concentração e relaxa a criança nos encontros clínicos.

\section{HIPÓTESES}

Na neuropsicologia a realização de atividade lúdica auxiliam no desenvolvimento de importantes áreas e habilidades cognitivas. Logo, vários pesquisadores relacionados a neurociência e a psicologia se mostram interessados em explicar as contribuições do lúdico no desenvolvimento infantil como forma de estimular o uso desse recurso nos diversos contextos da infância.

A utilização do lúdico na clínica de neuropsicologia se torna um importante recurso no diagnóstico e terapêutica de crianças que apresentam dificuldades e/ou atraso no desenvolvimento, pois sabe-se que o ato de brincar é algo intrínseco, espontâneo e projetivo da criança, surgindo como peça fundamental para comunicação, observação, coleta de informações e intervenção no processo de atendimento clínico.

\section{METODOLOGIA}

O presente trabalho, cuja pesquisa tem como área de conhecimento as ciências biológicas e humanas, visa enfatizar as contribuições do lúdico no desenvolvimento infantil e na Clínica de neuropsicologia, salientando que essas atividades lúdicas (brincadeiras, jogos, contação de histórias, desenhos, entre outros) tem uma importante contribuição na identificação das dificuldades neurológicas, emocionais e 
educacionais da criança, auxilia na terapêutica, estando respaldada em importantes e recentes autores.

Trata-se de uma pesquisa desenvolvida de cunho qualitativo, na busca de se compreender a natureza de um fenômeno que requer conhecimento em diversas áreas. Este método foi escolhido por proporcionar respostas às características que o estudo apresenta, levando-se em consideração ser a abordagem mais adequada. Este método valoriza a criatividade do pesquisador na condução de sua investigação, é um método flexível e não linear. Sua flexibilização dá método um caráter de questionar o novo, novos conceitos e paradigmas decorrentes de fenômenos sociais, a respeito destes aspectos Minayo (1992, p.98) destaca:

[...] Os métodos qualitativos apresentam as grandes possibilidades de operacionalização das concepções que emergem dos novos paradigmas. Esse método tem como foco interrogar sobre os fenômenos que ocorrem com seres humanos na vida social, mas especialmente a construção de marcas teóricas, a partir das próprias informações da realidade estudada e que, posteriormente, servirão de referências para outros estudos.

Esta pesquisa caracteriza-se como bibliográfica, por fazer uso de conteúdos disponíveis em livros, artigos e revistas especializadas, além de materiais disponíveis na web, com a finalidade de contrapor as ideias de vários teóricos a respeito do mesmo tema. Nesta perspectiva de busca, a pesquisa bibliográfica segundo Gil (1999, p.65) "permite ao investigador a cobertura, de uma gama de fenômeno muito mais amplo do que poderia pesquisar diretamente".

O objetivo primordial da investigação é, para além de encontrar resultados, analisar

e

compreender

consequentemente compreender melhor o método de ensino e aprendizagem infantil.

a

temática,

no

de desenvolver

apinorar

práticas clínicas e infantil.

Este estudo está organizado para fins de melhor disposição em capítulos, sendo que abordamos as principais concepções teóricas sobre as contribuições do lúdico na infância, até entrar na discussão deste como recurso lúdico contribui para a clínica no 
diagnóstico e intervenção, levando em conta a importância que tem este para o tratamento de crianças com dificuldades e/ou atraso no desenvolvimento.

Posteriormente, à pesquisa bibliográfica serão analisadas as informações, discussões teóricas, consideração final e referência bibliográfica. De semelhante forma espera-se contribuir com a disseminação de informações, à medida que vira alvos de debates entre profissionais e estudantes das diversas áreas.

\section{CONSIDERAÇÕES FINAIS}

Muitos estudiosos da neurologia e da psicologia, entre outras áreas tem explorado muitas questões sobre a importância do lúdico no desenvolvimento infantil, onde destacam sua relevância e significativa contribuição para a sua aprendizagem com influência em importantes áreas cognitivas;

A adoção de um recurso infantil baseado no lúdico em um atendimento terapêutico está relacionado sem dúvida a adoção de uma atividade importante na infância dentro de um contexto de cuidado em reabilitação, sobretudo na neuropsicologia, apesar de ser possível e indispensável pensá-la em diversos contextos e áreas de atuação de atenção básica.

O lúdico na clínica infantil ao ser utilizado como recurso favorece a comunicação, ampliando o repertorio verbal, podendo fortalecer o comportamento verbal na criança sobre o qual o terapeuta terá maiores condições de compreensão do que se passa com a criança fortalecendo essa comunicação, muitas vezes não verbal.

Na clínica de neuropsicologia a utilização da brincadeira torna se um importante aliado no diagnóstico e terapêutica de crianças que apresentam dificuldades e/ou atraso no desenvolvimento, pois se sabe que o ato de brincar é algo intrínseco, espontâneo e projetivo da criança e por esse motivo surge como peça fundamental para comunicação, observação, coleta de informações e intervenção no processo de atendimento clínico. 


\section{REFERÊNCIAS}

CUNHA, N. H. da S. Brinquedoteca: um mergulho no brincar. São Paulo: Maltese, 1994.

GADELHA, Yvanna Aires; MENEZES, Izane Nogueira de. Estratégias lúdicas na relação terapêutica com crianças na terapia comportamental. Univ. Ci. Saúde, Brasília, v. 2, n. 1, jan./jun. $2004 . \quad$ Disponível em: http://publicacoes.uniceub.br/index.php/cienciasaude/article/view/523/344.

Acesso em: 05 maio 2020.

GIL, Antonio Carlos. Métodos e técnicas de pesquisa social. São Paulo: Atlas, $5^{a}$ ed. 1999.

GUIMARÃES, Adriana I. \& SILVA, Carlos A. S. da. A Neurociência Do Lúdico Na Aprendizagem. Revista Acadêmica RPGM, São Paulo, v. 1, n. 1, p. 121-130, mar./jun. 2017. Disponível em: http://fics.edu.br/index.php/rpgm/article/view/475. Acesso em: 05 maio 2020.

KISHIMOTO, Tizuko Morchida. Froebel e a concepção de jogo infantil. In: (Org). O brincar e suas teorias. São Paulo: Pioneira Thomson Learning, 2002.

MALUF, Cristina Munhoz. Brincar, Prazer e Aprendizado. Editora Vozes. $3^{\underline{a}}$ edição. 2004.

MEYER, Ivanise. C. R. Brincar e Viver. Projetos em Educação Infantil. $2^{\underline{a}}$ ed. WAK Editora. Rio de Janeiro, RJ. 2004. 145 p

MINAYO, Maria Cecília de Souza. O desafio do Conhecimento: pesquisa qualitativa em saúde. 2. Ed., São Paulo: Hucitec/ Abrasco, 1992.

OLIVEIRA, Vera Barros (Org). O brincar e a criança do nascimento os seis anos. $11^{\mathrm{a}}$ edição. Editora Vozes. Petrópolis, RJ. 2014. 182 pg. 
PEREIRA, Mary Sue. A Descoberta da criança, introdução à educação infantil. Rio de Janeiro: Wak, 2004.

PIAGET, Jean. O nascimento da inteligência na criança. Rio de Janeiro, Zahar. 1975.

RELVAS, Marta Pires. Neurociências e Transtornos de Aprendizagem. As múltiplas eficiências para uma educação inclusiva. $6^{\underline{a}} \mathrm{ed}$. Ed. WAK Rio de Janeiro. 2015. $143 \mathrm{p}$.

RELVAS, Marta Pires. Neurociência: a aprendizagem e o brincar na infância; entenda essa relação. Vya Estelar. 2018. Disponível em: https://www.vyaestelar.com.br/post/11523/neurociencia-a-aprendizagem-e-o-brincarna-infancia-entenda-essa-relacao. Acesso em: 05 maio 2020.

SILVA, Vanussa S. D. da. O lúdico como recurso metodológico na inclusão de alunos com deficiência intelectual no ensino fundamental. Tese de Conclusão de Pós-graduação de Educação Especial e Inclusiva. UEMA. São Luís/MA. 2019. 22p.

SOUSA, E. C. M., FERNANDES, F. E. M. C., SILVA, H. C. M da. Enquanto eu brinco, eu aprendo?! Reflexões acerca da Neurociência. IV Colóquio Internacional Educação, Cidadania e Exclusão. Didática e Avaliação, 2015. Disponível em: http://docplayer.com.br/22898539-Enquanto-eu-brinco-eu-aprendo-reflexoes-acercada-neurociencia.html. Acesso em: 05 maio 2020.

SCHIMIDT, Andréia Aprendizagem do repertorio verbal na educação infantil: um estudo exploratório. Tese de mestrado. Biblioteca Virtual da FAPESP. FFCLRP/ USP. Ribeirão Preto. 2019.

Disponível em: https://bv.fapesp.br/pt/bolsas/173468/aprendizagem-do-repertorio-verbal-naeducacao-infantil-um-estudo-exploratorio/. Acesso em: 05 maio 2020.

VIGOTSKI, L.S. A construção do pensamento e da linguagem. São Paulo: Martins Fontes, 2000. 
VYGOSTSKY, L. S. A Formação Social da Mente. Martins Fontes - São Paulo. $5^{a}$ edição, 1994.

VYGOTSKY, Lev Semenovich. A formação social da mente. 6. ed. São Paulo: Martins Fontes, 1998.

WAJKOP, Gisela. Brincar na pré-escola. São Paulo: Cortez, 1999.

WEISS. Maria Lúcia Lemme. Vencendo as dificuldades de aprendizagem escolar. Rio de Janeiro: Wak Ed., 2010.

WINNICOTT, D. W. O brincar e a realidade. Trad. José Octavio de Aguiar Abreu e Vanede Nobre. Rio de Janeiro: Imago. 1975;

Enviado: Fevereiro, 2020.

Aprovado: Novembro, 2020. 